\title{
Dietary intake and development of a quantitative food-frequency questionnaire for the Barbados National Cancer Study
}

\author{
Sangita Sharma ${ }^{1, *}$, Xia Cao ${ }^{1}$, Rachel Harris ${ }^{2}$, Anselm JM Hennis ${ }^{2,3}$, M Cristina Leske ${ }^{3}$, \\ Suh-Yuh Wu ${ }^{3}$ and The Barbados National Cancer Study Groupt \\ 'Cancer Etiology Program, Cancer Research Center of Hawaii, University of Hawaii, 1236 Lauhala Street, Honolulu, \\ HI 96813, USA: ²Barbados National Cancer Study, Sir Winston Scott Polyclinic, Jemmott's Lane, St Michael, \\ Barbados: ${ }^{3}$ Department of Preventive Medicine, *Stony Brook University, Stony Brook, NY 11794, USA
}

Submitted 1 March 2006: Accepted 4 August 2006

\begin{abstract}
Objective: To develop a quantitative food-frequency questionnaire (QFFQ) for the Barbados National Cancer Study (BNCS) that will permit examination of associations of diet with breast and prostate cancer.

Design: Population intake data from the year 2000 Barbados Food Consumption and Anthropometric Surveys (BFCAS 2000) were used to derive a list of foods consumed by the population. A 192-item draft QFFQ was developed from this list.

Setting: Barbados, West Indies provides an ideal environment to understand cancer risk in African-origin populations, with high relevance to African-Americans. The BNCS is a population-based case-control study examining risk factors for breast and prostate cancer in such populations.

Subjects: A total of 1600 persons, 18 years and older, completed a 24-hour recall in the BFCAS 2000. Fifty of 63 randomly selected residents (79\% response rate) gave additional updated information on foods consumed.

Results: The 50 participants provided a one-time 24-hour recall and completed the draft QFFQ. The final instrument contains 148 items: breads, cakes, cereals $=17$; rice, pastas, noodles $=8$; dairy $=10$; meat, fish, poultry $=42$; fruit $=16$; vegetables $=26$; soft drinks $=14$; alcoholic beverages $=5$; others $=10$. Additional questions include supplement use and food preparation methods such as grilling.

Conclusion: The final instrument is concise, complete and the most up-to-date for assessing the food and nutrient intake of African-origin Barbadians and the associations with breast and prostate cancer.
\end{abstract}

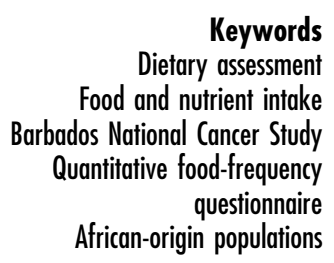

Keywords

Dietary assessment Food and nutrient intake ados National Cancer Study questionnaire African-origin populations
The Barbados National Cancer Study (BNCS) is a population-based case-control study examining risk factors for breast and prostate cancer in an African-origin population. Although both cancers are particularly important causes of morbidity and mortality in persons of African descent ${ }^{1}$, the underlying reasons for these cancer disparities are unknown. Barbados, West Indies, with a population of $>270000$ ( $>90 \%$ of African descent), provides an ideal environment to understand cancer risk in African-origin populations. African-Barbadians (AfBas)

†Coordinating Center, Department of Preventive Medicine, Stony Brook University, Stony Brook, NY, USA: M Cristina Leske, Barbara Nemesure, S-Y Wu. Clinical Center, Ministry of Health, Barbados, and University of the West Indies, Bridgetown, Barbados: Anselm Hennis, Rachel Harris, Lynda Williams, Lyndon Waterman. NHGRI Center, National Human Genome Research Institute, Bethesda, MD, USA: Joan Bailey-Wilson. Gene Discovery Center, Translational Genomics Institute, Phoenix, AZ, USA: John Carpten, Jeffrey Trent. Cancer Etiology Program, Cancer Research Center of Hawaii, University of Hawaii, Honolulu, HI, USA: Sangita Sharma, Xia Cao. and African-Americans share a common ancestry, but AfBas remained fairly isolated with lesser subsequent admixture $^{2-4}$; they are therefore an appropriate reference group for comparisons with African-Americans regarding genetic and environmental risk factors for these cancers. However, associations with these potential factors have not been examined in AfBas. There has never been a method to assess long-term dietary intake in Barbados, thus precluding association studies between diet and cancer.

Due to the importance of nutrition-related factors and growing interest in the role of nutrient-gene interactions in cancer aetiology, the development of a method for assessing long-term dietary intake is of paramount importance. The aim of this report is to describe the development of a quantitative food-frequency questionnaire (QFFQ) for the BNCS, which can be used to examine associations of diet with breast and prostate cancer, as well as to test emerging hypotheses on nutrient-gene interactions. No such QFFQ exists for Barbados, and currently there are very limited data on food composition of 
composite dishes and usual portion size consumed, two essential requirements for analysing a QFFQ. We provide information on how we obtained and analysed these data to develop the QFFQ for the BNCS.

\section{Methods}

\section{Sources of data}

Barbados Food Consumption and Antbropometric Survey (BFCAS)

In 2000, the BFCAS obtained 24-hour recall data from a nationwide population sample, based on a systematic random two-stage cluster design ${ }^{5}$. A total of 1704 respondents from 1051 households participated in the survey (average age of 48.9 years (standard deviation 17.6)), and included 945 (55.5\%) women. A total of $60.0 \%$ were employed, $44.2 \%$ had completed secondary education, and 10.0 and $17.3 \%$, respectively, reported diabetes and hypertension. A subset of 1600 respondents completed a detailed dietary intake assessment using the 24-hour recall, and were included in the final data analysis.

A complete list of all foods, beverages and supplements reported during the survey was obtained from the Ministry of Health. Household units such as cups, teaspoons and tablespoons had been shown to the participants to aid their estimation of portion size.

\section{Pilot study for the draft QFFQ}

The pilot study involved the development of a draft QFFQ and the administration of a 24 hour recall. The respective methods and training protocols follow.

Draft $Q F F Q$. Any food item that was reported by at least two of the 1600 BFCAS respondents was listed to provide foods for a draft QFFQ. Foods low in energy and nutrients, such as condiments and spices, were not included as their contribution to overall dietary intake was minor. Additional foods that had not appeared in those BFCAS recalls but were considered relevant to the BNCS, such as soy products and seasonal foods that may have been omitted, were added to the draft QFFQ. Additional blank lines were added under each food group on the draft QFFQ for respondents to list any additional foods or drinks that they consumed frequently. This draft QFFQ was pilot tested in a sample of individuals randomly selected from a nationwide database of Barbados citizens 21 years and older, updated for 2004-2005. This sampling methodology was used to select BNCS population-based controls, as well as participants in previous epidemiologic studies ${ }^{6}$.

Two interviewers (one nurse and one dietitian) were trained for 5 days in the administration of the instrument and a manual of procedures was developed to document all protocols to be followed. To ensure standardisation of the data collection, each interviewer practised multiple pilot QFFQ administrations, under the supervision of the first author (S.S.). To evaluate the ease of completing the draft QFFQ, additional questions were included to obtain the respondents' opinion on the instrument and suggestions for improvement.

Twenty-four hour recall. Individuals in the sample selected for pilot testing were also asked to complete one 24-hour recall interview before completing the interviewer-administered draft QFFQ. These 24-hour recall interviews systematically sought and recorded information about foods and drinks consumed during the preceding 24 hour period. Portion size was assessed using familiar household units such as a pot spoon of rice, using standard units such as a slice of bread, or using threedimensional models (NASCO) that had been carefully chosen to estimate best the amount consumed. Each interviewer was given a set of food models as well as bowls, cups, glasses and spoons. Interviews were conducted at home or in the BNCS office by the same dietitian and nurse mentioned above, who were also trained for collection of 24-hour recalls and supervised by S.S. Data from each 24-hour recall were recorded on dietary assessment forms. An additional list of questions was included to prompt for easily forgotten foods such as sweets, alcohol and snacks. We also included questions on any special dietary practices the respondent followed such as a weight loss diet, or a low fat diet. All data were examined by the project coordinator and, if any data were incomplete, the interviewer was asked to re-contact the respondent for the additional information. Recalls covered both weekdays and weekends in March 2004. Both respondents and interviewers were also asked to complete a separate evaluation form of the instrument.

The study was approved by the University of the West Indies Research Ethics Review Committee and the Stony Brook University Committee on Research Involving Human Subjects. All participants signed informed consent forms before their interviews took place.

\section{Data on nutrition composition of mixed dishes}

To calculate the nutrient composition of foods reported in the recalls and listed on the QFFQ, it was necessary to collect additional data involving weighed recipes of dishes, as there were limited data available on the composition of these dishes. For this additional step, S.S. trained and certified a dietitian and a nurse for 3 days in how to collect, record and weigh ingredients for composite dishes. A recipe collection form and a manual of procedures were developed. The trained dietitian and nurse collected recipes from BNCS participants and volunteers. The dietitian and nurse scheduled appointments at the homes of these volunteers, where they weighed all the ingredients and the final cooked weight of the dishes. For most of the 35 composite dishes involved in this process, five different recipes were collected. An average recipe was then calculated for each dish. The dietitian attempted to obtain weighed recipes from at least six different households of varied socio-economic 
status, to be representative of the Barbadian population. Individuals were reimbursed for the cost of the ingredients.

To derive weights from portion sizes that respondents reported consuming in the 24-hour recalls, the dietitian and S.S. weighed portions for all reported foods. For example, 10 rotis were weighed from many sources including home made, and an average weight obtained. Weights were also obtained for all household units for each food item recorded, such as taking the average of 10 pot spoons of rice and of rice and peas and lasagna. All food weights were obtained using an electronic kitchen scale (Aquatronic Baker's Dream Scale (11lb); Salter Houseware Ltd).

All data were entered into Excel to calculate the average weights.

\section{Analyses}

Nutrient intakes of respondents were estimated from the single interviewer-administered 24-hour recalls. All dietary data were coded and entered by a graduate nutrition student (X.C.) and analysed using Nutribase Clinical Nutrition Manager version 5.18 (Cybersoft Inc.), which calculated nutrient intakes per person. The food composition tables in Nutribase were updated to include the weighed recipes. All other data analyses were undertaken using SAS version 9.1 (SAS Inc.).

Foods that were reported as being consumed on the one-time 24-hour recall were compared with the foods listed in the draft QFFQ. This was done to ensure that no foods had been omitted and that currently available foods were included, as the BFCAS ${ }^{5}$ had been undertaken 4 years previously.

\section{Results}

Fifty of the 63 individuals contacted participated (79\% response rate). This group of 22 men and 28 women provided the 24-hour recalls and completed the draft QFFQ. The population sample consisted of adults with a mean age for men and women of 53.9 years and 51.4 years, respectively (Table 1). All foods reported at least twice in the recalls had been included on the draft QFFQ, showing it to be complete and up to date.

A total of 160 recipes were collected for 35 composite dishes. The mean nutrient composition was calculated for the 35 dishes. In addition, we obtained $\sim 350$ average portion weights for all food and drink items reported in the 24-hour recalls and on the QFFQ.

\section{Nutrient intakes}

Table 1 describes the nutrient intake of the participants based on 49 dietary recalls; the remaining recall was excluded as an outlier ( $>5000 \mathrm{kcal}$ of daily energy intake). As our sample size is small and the purpose of the recalls was primarily to ensure the food list for the QFFQ was up to date, we present and discuss limited nutrient intake results.

Whilst the overall energy intake was somewhat lower than expected (mean daily energy intake for men $2114 \mathrm{kcal}$ and $1646 \mathrm{kcal}$ for women), 28\% had reported eating less than usual on the day of the recall and $61 \%$ of participants reported being on a special diet, which would probably have resulted in a lower energy intake. The special diets reported were low-fat, low-sugar, diabetic and higher-fibre diets.

Table 1 Mean and median daily energy and nutrient intake of the BNCS participants obtained from the 24-hour recalls and the BFCAS*

\begin{tabular}{|c|c|c|c|c|c|c|}
\hline & \multicolumn{3}{|c|}{ Women } & \multicolumn{3}{|c|}{ Men } \\
\hline & \multicolumn{2}{|c|}{ BNCS } & \multirow[b]{2}{*}{ BFCAS } & \multicolumn{2}{|c|}{ BNCS } & \multirow[b]{2}{*}{ BFCAS } \\
\hline & Mean $\pm S D$ & Median & & Mean $\pm S D$ & Median & \\
\hline Number & 27 & 27 & 199 & 22 & 22 & 161 \\
\hline Age (years) & $51.4 \pm 13.0$ & 49 & $50-64$ & $53.9 \pm 16.9$ & 51 & $50-64$ \\
\hline Energy (kcal) & $1646 \pm 677$ & 1520 & 1698 & $2114 \pm 794$ & 1854 & 2002 \\
\hline Saturated fat (g) & $14.6 \pm 10.6$ & 11.5 & $\mathrm{n} / \mathrm{a}$ & $14.0 \pm 9.2$ & 12.3 & $\mathrm{n} / \mathrm{a}$ \\
\hline Protein (g) & $63.5 \pm 31.9$ & 57.3 & 69.5 & $77.3 \pm 34.5$ & 68.0 & 85.5 \\
\hline Carbohydrate (g) & $231.4 \pm 105.1$ & 210 & 245 & $326.2 \pm 144.5$ & 275 & 277 \\
\hline Sugar $(g)$ & $108.5 \pm 76.0$ & 82.6 & $\mathrm{n} / \mathrm{a}$ & $156.3 \pm 103.8$ & 116.9 & $\mathrm{n} / \mathrm{a}$ \\
\hline Dietary fibre (g) & $15.6 \pm 7.6$ & 15.1 & $\mathrm{n} / \mathrm{a}$ & $18.2 \pm 8.4$ & 16.8 & $\mathrm{n} / \mathrm{a}$ \\
\hline Vitamin C (mg) & $110.7 \pm 127.0$ & 75.8 & 62.1 & $185.0 \pm 165.2$ & 144.8 & 57.4 \\
\hline Vitamin A ( $\mu \mathrm{g}$ RE) & $815 \pm 731$ & 638 & 760 & $1744 \pm 1263$ & 1534 & 1000 \\
\hline Vitamin D (IU) & $60.3 \pm 103.5$ & 13.2 & $\mathrm{n} / \mathrm{a}$ & $26.3 \pm 34.4$ & 5.0 & $\mathrm{n} / \mathrm{a}$ \\
\hline Iron (mg) & $11.8 \pm 8.0$ & 10.3 & 11.9 & $16.4 \pm 12.4$ & 12.6 & 14.5 \\
\hline$\%$ energy from total fat & $27.2 \pm 9.3$ & 27.8 & $26.3 \dagger$ & $22.2 \pm 7.5$ & 22.5 & $22.2 \dagger$ \\
\hline$\%$ energy from carbohydrate & $56.4 \pm 12.1$ & 57.8 & $57.7 \dagger$ & $60.4 \pm 12.2$ & 62.3 & $55.3 \dagger$ \\
\hline$\%$ energy from protein & $15.1 \pm 4.0$ & 14.4 & $16.4 \dagger$ & $14.5 \pm 3.8$ & 14.3 & $17.1 \dagger$ \\
\hline
\end{tabular}

BNCS - Barbados National Cancer Study; BFCAS - Barbados Food and Consumption and Anthropometric Surveys: SD - standard deviation; RE - retinol equivalents; $\mathrm{n} / \mathrm{a}$ - data not available.

${ }^{*}$ Only median available in this study ${ }^{5}$.

† Comparable data not available; therefore calculated by the authors. 
Data are also presented from the BFCAS, based on 24-hour recalls in people aged 50-64 years ${ }^{5}$. Median energy intakes from our study are similar, although slightly lower (150$200 \mathrm{kcal})$, than those reported in the BFCAS ${ }^{5}$. In general, the median nutrient intakes are similar between the BNCS and the BFCAS population samples ${ }^{5}$, except for vitamin A and vitamin $\mathrm{C}$ which are higher in the BNCS men, and this may be a reflection of seasonal consumption of fruits or vegetables in the BNCS as recalls were collected during March only.

The percentage of energy provided by fat was $\sim 22 \%$ for men and $28 \%$ for women, similar to those reported in the BFCAS $^{5}$, and is also probably reflective of the numbers who reported following a low-fat $\operatorname{diet}^{7}$. Mean daily calcium and dietary fibre intakes were low for both men and women.

\section{The $Q F F Q$}

Administration of the draft QFFQ was lengthy, and both respondents and interviewers suggested reducing its length. To shorten the 192-item draft QFFQ to contain only significant contributors of energy and nutrients, foods that were reported fewer than six times in the 50 24-hour recalls or the draft QFFQ and contributed little to nutrient intake $(<0.5 \%)$ were excluded, with the exception of whole milk and alcoholic drinks. Foods that were similar in nutritional composition (such as cakes) were combined. As a result, the final QFFQ contains 148 food and drink items and includes 17 items of bread, cakes and cereals; eight items of rice, pastas and noodles; 10 dairy items; 42 items of meat, fish and poultry; 16 fruit items; 26 vegetable items; 14 items of soft drinks; five items of alcoholic beverages; and 10 other food items.

Additional questions were included on supplement use, and meat preparation methods such as grilling, in order to be able to determine heterocyclic amine intake.

The foods listed on the final QFFQ are shown in Appendix A.

Appendix B displays a sample page of the final QFFQ and the frequency categories which range from 'never or less than 1 time per month' to ' 2 or more times per day'. The QFFQ assesses usual food and drink intake consumed over the last 12 months. Portion size is assessed using a household unit such as a cooked spoon or coffee mug for 33 items, using a food model for 64 items and using a standardised portion such as a slice of bread or a cracker for 51 items. The final QFFQ takes $\sim 35$ min to administer.

\section{Discussion}

To develop an FFQ, three steps are needed: compose the food list; define the portion sizes; and assign nutrient values to each food item ${ }^{8}$. Obtaining an appropriate food list for a specific population is the most critical step in the process of developing an FFQ. The foods selected must be: (1) commonly consumed by a substantial segment of the population; (2) contain significant amount of nutrients of interest, or foods of interest; and (3) have a great variety of consumption among the people ${ }^{9-11}$. We compiled our food list by aggregating the foods collected from 24-hour recalls of 1600 participants in the BFCAS and by collecting additional up-to-date 24-hour recalls from a population-based sample of 50 individuals. Establishing a food list for the development of the QFFQ, based on national or community surveys, is a method used by many other researchers ${ }^{8,12,13}$.

Portion sizes were assessed using appropriate food models to assist participants in describing their usual amounts consumed, as has been done in other studies ${ }^{14}$. We used eight categories of frequency in ascending order, in the final QFFQ.

We have obtained, for the first time, detailed amounts of ingredients and foods in 160 recipes for 35 dishes commonly consumed in Barbados, from which we calculated nutrient composition values. While we appreciate that biochemical analysis is ideal, this is extremely expensive and such funding was not available. There were no other published data on food composition for mixed dishes consumed in Barbados. The Caribbean food tables did not contain most of the foods eaten as mixed dishes nor did they contain the full range of nutrients of interest for our cancer analysis ${ }^{15,16}$.

Although our sample size was small and the primary purpose of the recalls was not to assess nutrient adequacy, clearly some nutrient intakes were less than recommended especially for calcium and fibre, which is similar to that reported in the BFCAS $^{5}$.

Fat intakes reported in the BNCS pilot study were relatively low, a finding also reported by the BFCAS ${ }^{5}$. The latter survey found that the percentage of calories derived from fat in the Barbadian diet (close to 25\%) was below the World Health Organization (WHO)-recommended maximum of $30 \%$, but above the recommended Caribbean maximum of $15-20 \%$.

The BFCAS also noted that as many as 50 and 33\% of persons diagnosed with diabetes and hypertension, respectively, claimed to follow special diets related to their conditions ${ }^{5}$. This observation is relevant to the high proportion of our pilot sample who similarly reported special diets.

A comprehensive dietary assessment strategy is essential for understanding the relationship between nutrition and diseases. FFQs have advantages over other dietary assessment methods, such as short-term recalls and diet records, because they are relatively inexpensive and can measure usual long-term dietary intake, especially for large population samples as in our study ${ }^{9,17,18}$. Though shortterm recalls or dietary records provide more precise data than FFQs, the research question regarding the relationship between diet and chronic diseases focuses on whether a specific food or nutrient is frequently consumed or never eaten ${ }^{9}$. The QFFQ is appropriate for the BNCS to assess the usual food and nutrient intake 12 months prior to the date of cancer diagnosis for cases or a comparable reference date for controls. These data can be used to examine the association between past dietary intake and incident breast and prostate cancer. 
Some limitations exist with this study. Deleting infrequently used food items from the QFFQ may omit some foods with higher between-person variation, but we only omitted those foods that would contribute little to the overall diet. At this point, validation of the instrument is currently underway, using 4-day food diaries and a repeat QFFQ.

Overall, a draft QFFQ was developed from 24-hour recall records obtained from a sample of 1600 participants. The additional data we collected from the 50 24-hour recalls enabled us to revise the draft QFFQ to develop an appropriate QFFQ for the African-origin populations in Barbados.

The QFFQ is presently being used in the BNCS to allow future assessments of: (1) overall nutrient intake; (2) food group intake; (3) the association of some nutrient intakes with the risk of breast and prostate cancer; (4) the association of the dietary patterns with the risk of breast and prostate cancer; and (5) eventual hypotheses on nutrient-gene interactions.

\section{Conclusion}

The final QFFQ contained 148 items, is up to date and will provide a comprehensive tool for assessing overall dietary intake, which can be used to determine associations of diet with prostate and breast cancer in AfBas. This is the first time a QFFQ has been developed from a representative population sample for Barbados. The instrument will also allow us to examine our hypotheses related to nutrient-gene interactions.

\section{Acknowledgements}

The BNCS was funded by the US National Human Genome Research Institute National Institutes of Health, Contract \# N01-HG-25 487. This research was also aided by the Developmental Funds award from the Cancer Research Center of Hawaii. We are also grateful to the Ministry of Health, Barbados, and the Food and Agriculture Organization of the United Nations for conducting the Barbados Food Consumption and Anthropometric Survey 2000. We thank all staff and participants in the Barbados National Cancer Study, without whose help the QFFQ data could not have been collected.

\section{References}

1 Ries LAG, Eisner MP, Kosary CL, Hankey BF, Miller BA, Clegg L, et al., eds. SEER Cancer Statistics Review, 1975-2002 [online]. Bethesda, MA: National Cancer Institute, based on November 2004 SEER data submission, posted to the SEER website 2005. Available at http://seer.cancer.gov/csr/ 1975_2002/

2 Goodridge R. The African background of the Barbados population. In: Cobley AG, Thompson A, eds. The
African-Caribbean Connection: Historical and Cultural Perspectives. Bridgetown, Barbados: Department of History, University of the West Indies, 1990; 28-48.

3 Cobley AG, Thompson A, eds. The African-Caribbean Connection: Historical and Cultural Perspectives. Bridgetown, Barbados: Department of History, University of the West Indies, 1990.

4 Hoyos FA. Barbados Comes of Age: From Early Strivings to Happy Fulfilment, 2nd ed. London: Macmillan Publishers Ltd, 1987.

5 Food and Agriculture Organization of The United Nations (FAO) \& The National Nutrition Center Ministry of Health, Government of Barbados. The Barbados Food Consumption and Anthropometric Survey 2000. Rome: FAO, 2005.

6 Leske MC, Connell AM, Schachat AP, Hyman L. The Barbados Eye Study. Prevalence of open angle glaucoma. Archives of Ophthalmology 1994; 112: 821-9.

7 Sharma S, Jackson M, Mbanya JC, Cade J, Forrester T, Wilks $\mathrm{R}$, et al. Development of food frequency questionnaires in three population samples of African origin from Cameroon, Jamaica and Caribbean migrants to the UK. European Journal of Clinical Nutrition 1996; 50: 479-86.

8 Shahar D, Fraser D, Shai I, Vardi H. Development of a food frequency questionnaire (FFQ) for an elderly population based on a population survey. Journal of Nutrition 2003; 133: 3625-9.

9 Willett W. Nutritional Epidemiology. New York: Oxford University Press, 1998.

10 Stark A. An historical review of the Harvard and the National Cancer Institute food frequency questionnaires: their similarities, differences, and their limitations in assessment of food intake. Ecology of Food and Nutrition 2002; 41: 35-74.

11 Cade J, Thompson R, Burley V, Warm D. Development, validation and utilization of food frequency questionnaires a review. Public Health Nutrition 2002; 5: 567-87.

12 Block G, Hartman AM, Dresser CM, Carroll MD, Gannon J, Gardner L. A data-based approach to diet questionnaire design and testing. American Journal of Epidemiology 1986; 124: 453-69.

13 Subar AF, Midthune D, Kulldorff M, Brown CC, Thompson FE, Kipnis V, et al. Evaluation of alternative approaches to assign nutrient values to food groups in food frequency questionnaires. American Journal of Epidemiology 2000; 152: $279-86$.

14 Sharma S, Cade J, Landman J, Cruickshank JK. Assessing the diet of the British African-Caribbean population; frequency of consumption of foods and food portion sizes. International Journal of Food Sciences and Nutrition 2002; 53: 439-44.

15 The Caribbean Food and Nutrition Institute, the Pan American Health Organization, Pan American Sanitary Bureau, Regional Office of the World Health Organization. Food Composition Tables for Use in the English-speaking Caribbean, 2nd ed. Kingston, Jamaica: Caribbean Food and Nutrition Institute, 1998.

16 The Caribbean Food and Nutrition Institute, the Pan American Health Organization, Pan American Sanitary Bureau, Regional Office of the World Health Organization. Food Composition Tables for Use in the English-speaking Caribbean, 2nd ed. Kingston Jamaica: Caribbean Food and Nutrition Institute, 2000.

17 Solomons NW, Valdes-Ramos R. Dietary assessment tools for developing countries for use in multi-centric, collaborative protocols. Public Health Nutrition 2002; 5: 955-68.

18 Taren D, Dwyer J, Freedman L, Solomons NW. Dietary assessment methods: where do we go from here? Public Health Nutrition 2002; 5: 1001-3. 
Appendix A - Food and drink items listed on the final QFFQ

\begin{tabular}{|c|c|}
\hline Category & Food items \\
\hline Breads, cakes and cereals (17) & $\begin{array}{l}\text { Salt bread, white; Salt bread, whole wheat; Turnover, white/whole wheat; Buns, hotdog buns, } \\
\text { rolls; Other white bread; Other whole wheat bread; Crackers, white/whole wheat; Coconut } \\
\text { bread; Cake; Doughnuts, currant slices, jam puffs; Sweet biscuits; Conkies; Cornflakes, Rice } \\
\text { Krispies, Bran Flakes; Weetabix, Shredded Wheat; Hot porriage; Granola/muesli; Bakes }\end{array}$ \\
\hline Rice, pastas, noodles (8) & $\begin{array}{l}\text { Rice and peas; Plain rice; Pilau; Rice and vegetables; Macaroni pie; Spaghetti/macaroni/ } \\
\text { noodles/chow mein; Bajan soup; Dumplings }\end{array}$ \\
\hline Dairy (10) & $\begin{array}{l}\text { Full cream milk; Milk, } 2 \% \text {; Condensed milk; Evaporated milk - full cream; Evaporated milk low fat; } \\
\text { Flavoured milks or milkshakes; Hard cheese, cheddar; Ice cream; Eggs; Soy milk }\end{array}$ \\
\hline Meats, poultry, fish, soy products (42) & $\begin{array}{l}\text { Seasoned mince beef/ground beef/beef stew; Lasagne; Shepherd's pie; Hamburgers; Meat } \\
\text { patties/rolls; Roti; Lamb stew; Lamb grilled/baked; Pork stew; Ham or pork grilled/roast/ } \\
\text { baked; Steam pudding; Souse; Sausages, hotdogs, frankfurters; Bacon; Pre-packaged sliced } \\
\text { meats (ham/turkey); Pre-packaged sliced meats (salami/bologna); Corn beef or luncheon } \\
\text { meat; Liver; Chicken giblets fried; Chicken, fried; Chicken, barbequed/baked/grilled/rotisserie; } \\
\text { Turkey wings; Stew chicken; Tuna, in oil; Tuna, in brine/water; Mackerel, in oil/tomato sauce; } \\
\text { Mackerel, in brine/water; Sardines, in oil/tomato sauce; Sardines, in brine/water; Salmon, } \\
\text { in brine/water; Fish cakes; Saltfish, cooked; White flesh fish, grilled/baked; White fish, } \\
\text { steamed/poached/boiled; White fish, fried; Flying fish, steamed/poached/boiled; Flying fish, } \\
\text { fried; White fish, banga-marie, butter fish, snapper - steamed/poached/boiled; White fish, } \\
\text { banga-marie, butter fish, snapper - fried; Cou Cou; Tofu, soy chunks; Soy burger, vita burger, } \\
\text { grain burger }\end{array}$ \\
\hline Fruits (16) & $\begin{array}{l}\text { Banana; Apple; Golden apple; Orange, tangerine; Grapefruit; Grapes; Pawpaw; Mango, fresh; } \\
\text { Local plums/hog plums; Plums, imported; Water melon, honey dew, musk or cantaloupe; } \\
\text { Guava; Pineapple, fresh; Fruit salad, fresh; Tinned fruit; Ackees/Guineps }\end{array}$ \\
\hline Vegetables (26) & $\begin{array}{l}\text { English potatoes, creamed/mashed; English potatoes, fried; English potatoes, baked/boiled; } \\
\text { Potato salad; Sweet potato, baked/boiled; Yam, baked/boiled/creamed; Cassava, boiled; } \\
\text { Breadfruit, boiled/pickled/roasted; Breadfruit, cou cou/crushed; Green banana, boiled/pickled; } \\
\text { Green banana, cou cou/crushed; Plantain, boiled; Plantain, fried; Mixed vegetables; Broccoli; } \\
\text { Cauliflower; Coleslaw; Carrots; String beans; Pumpkin or squash; Corn; Okra; Avocado; } \\
\text { Cabbage, spinach and other dark green leafy vegetables; Tomatoes; Tossed salad }\end{array}$ \\
\hline Other foods (10) & $\begin{array}{l}\text { Pizza; Nuts; Peanut butter; Chips; Chocolate bar; Sugar cake, tamarind balls, peanut cake; } \\
\text { Candy, sweets, mints; Margarine; Gravy, homemade, with meat dripping; Gravy, homemade, } \\
\text { without meat dripping }\end{array}$ \\
\hline Soft drinks (14) & $\begin{array}{l}\text { Sweetened fruit juice, pineapple, golden apple grape, orange, grapefruit, guava, passion fruit, } \\
\text { fruit punch, other; Sweetened fruit juice Bajan cherry, black currant; Unsweetened fruit juice; } \\
\text { Kool Aid, Tang, Fresh Start; Homemade drinks; Carbonated soft drinks, regular; Diet } \\
\text { carbonated soft drinks; Coconut water; Ovaltine, Horlicks, Milo, Bournvita, malt drink, hot } \\
\text { chocolate, cocoa (dry powder); Boost, Lasco, Nutrament, Complan, Ensure, Enterex DM, } \\
\text { Choice DM, Glucerna; Tea, black; Tea, herbal, fruit, green; Coffee; Honey/syrup/sugar }\end{array}$ \\
\hline Alcohol (5) & Wine, white; Wine, red; Liquor; Beer; Stout, malt \\
\hline
\end{tabular}


Appendix B - A sample page of the QFFQ

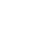

HOW OFTEN during the 12 month period prior to (Reference Date) did you usually eat the following foods \& how much do you usually eat at one time?

\begin{tabular}{|c|c|c|c|c|c|c|c|c|c|c|}
\hline Food & Portion & & $\begin{array}{l}\text { Never } \\
<1 / \text { mo }\end{array}$ & $\begin{array}{l}\text { Once a } \\
\text { month }\end{array}$ & $\begin{array}{l}2-3 x a \\
\text { month }\end{array}$ & $\begin{array}{l}\text { Once a } \\
\text { week }\end{array}$ & $\begin{array}{l}2-3 x a \\
\text { week }\end{array}$ & $\begin{array}{l}4-6 \times a \\
\text { week }\end{array}$ & $\begin{array}{l}\text { Once } \\
\text { a day }\end{array}$ & $\begin{array}{r}2 \text { or }>x \\
\text { a day }\end{array}$ \\
\hline $\begin{array}{l}\text { Breads, cakes and cereals } \\
\text { 1. Salt bread,white }\end{array}$ & & $\#$ & $O(1)$ & $\mathrm{O}(2)$ & $O(3)$ & $\mathrm{O}(4)$ & $O(5)$ & $O(6)$ & $O(7)$ & $\mathrm{O}(8)$ \\
\hline 2. Salt bread, whole wheat & & $\#$ & $O(1)$ & $O(2)$ & O (3) & O (4) & $\bigcirc(5)$ & $\mathrm{O}(6)$ & $O(7)$ & $\mathrm{O}(8)$ \\
\hline 3. Turnover, white/whole wheat & & $\#$ & $O(1)$ & O (2) & O (3) & O (4) & O (5) & $O(6)$ & $O(7)$ & O (8) \\
\hline 4. Buns, hot dog buns, rolls & & $\#$ & $O(1)$ & $O(2)$ & $O(3)$ & $O(4)$ & $O(5)$ & $O(6)$ & $O(7)$ & O (8) \\
\hline 5. Other white bread & & $A$ & $O(1)$ & $O(2)$ & $O(3)$ & $O(4)$ & $O(5)$ & $O(6)$ & $O(7)$ & $\bigcirc(8)$ \\
\hline 6. Other whole wheat bread & & A & $\mathrm{O}(1)$ & $O(2)$ & O (3) & $\bigcirc(4)$ & $O(5)$ & $\mathrm{O}(6)$ & $O(7)$ & $O(8)$ \\
\hline $\begin{array}{l}\text { 7. Crackers, white/whole wheat } \\
\text { (Sodabix, Eclipse, Wibix, Crix) }\end{array}$ & & $\#$ & $O(1)$ & $O(2)$ & $\mathrm{O}(3)$ & $O(4)$ & $O(5)$ & $O(6)$ & $O(7)$ & $\bigcirc(8)$ \\
\hline 8. Coconut bread & & B & $O(1)$ & $O(2)$ & $O(3)$ & $O(4)$ & $O(5)$ & $O(6)$ & $O(7)$ & $O(8)$ \\
\hline 9. Cake, any kind & & $\mathrm{C}$ & $O(1)$ & $O(2)$ & $O(3)$ & $O(4)$ & $O(5)$ & $O(6)$ & $O(7)$ & $O(8)$ \\
\hline 10. Doughnuts, currant slices, jam puffs & & $\#$ & $O(1)$ & $O(2)$ & O (3) & $\mathrm{O}(4)$ & $\mathrm{O}(5)$ & $O(6)$ & $\mathrm{O}(7)$ & $\mathrm{O}(8)$ \\
\hline $\begin{array}{l}\text { 11. Sweet biscuits } \\
\text { (Teatime, Digestive, Shirley, Ovaltine) }\end{array}$ & & $\#$ & $O(1)$ & $O(2)$ & $O(3)$ & $O(4)$ & $O(5)$ & $O(6)$ & $O(7)$ & $\circ(8)$ \\
\hline 12. Conkies (in season) & & \# & $O(1)$ & $O(2)$ & $O(3)$ & O (4) & $\mathrm{O}(5)$ & $\mathrm{O}(6)$ & $\mathrm{O}(7)$ & $\mathrm{O}(8)$ \\
\hline $\begin{array}{l}\text { 13. Cold cereals: Cornflakes, Rice } \\
\text { Krispies, Bran Flakes }\end{array}$ & & $\#$ & $\circ(1)$ & ○ (2) & O (3) & $\bigcirc(4)$ & ○ (5) & $\bigcirc(6)$ & $O(7)$ & $\bigcirc(8)$ \\
\hline 14. Weetabix,Shredded Wheat & & \# & $O(1)$ & $O(2)$ & $O(3)$ & O (4) & O (5) & $O(6)$ & $O(7)$ & $O(8)$ \\
\hline
\end{tabular}

Enrollment Number $\square-$\begin{tabular}{|l|l|l|l|}
\hline & & & \\
\hline
\end{tabular} 